\title{
Oral Probiotic Expressing Human Ethanol Dehydrogenase Attenuates Damage Caused by Acute Alcohol Consumption
}

\section{Xiaoxiao Jiang}

Chinese Academy of Sciences Key Laboratory of Animal Ecology and Conservation Biology

Chunlong Yan

Yanbian University Agriculture College

\section{Shouli Yuan}

Chinese Academy of Sciences Key Laboratory of Animal Ecology and Conservation Biology

\section{Hanlin Zhang}

Chinese Academy of Sciences Key Laboratory of Animal Ecology and Conservation Biology

\section{Rongcai Ye}

Chinese Academy of Sciences Key Laboratory of Animal Ecology and Conservation Biology

\section{Huiqiao Zhou}

Chinese Academy of Sciences Key Laboratory of Animal Ecology and Conservation Biology

\section{Li Chen}

Chinese Academy of Sciences Key Laboratory of Animal Ecology and Conservation Biology

\section{Rui Jiang}

Chinese Academy of Sciences Key Laboratory of Animal Ecology and Conservation Biology

Kexin Zheng

Capital Medical University Affiliated Beijing Ditan Hospital

\section{Yuanyuan Huang}

Chinese Academy of Sciences Key Laboratory of Animal Ecology and Conservation Biology

\section{Wanzhu Jin}

Chinese Academy of Sciences Key Laboratory of Animal Ecology and Conservation Biology

\section{Gang Sun}

Chinese PLA General Hospital Fifth Medical Center

\section{Meng Dong}

Chinese Academy of Sciences Key Laboratory of Animal Ecology and Conservation Biology

Xiaomeng Liu ( $\square$ lxmxm_99@126.com )

Xinxiang Medical University https://orcid.org/0000-0002-5524-0226

\section{Research}


Keywords: human ADH1B, Recombinant probiotics, alcohol decomposition, alcoholic fatty liver, Oral administration

Posted Date: October 25th, 2021

DOI: https://doi.org/10.21203/rs.3.rs-966674/v1

License: (1) This work is licensed under a Creative Commons Attribution 4.0 International License. Read Full License 


\section{Abstract}

Alcohol is an essential drug in human life with multiple medical functions, but excessive alcohol intake, even a single episode of binge-drinking, can cause serious damage. Reducing alcohol consumption or absorption is a direct way to alleviate this harm. Alcohol is decomposed successively by alcohol dehydrogenase (ADH) and acetaldehyde dehydrogenase (ALDH) in the liver. Many anti-hangover drugs are intended to increase the activity of these two enzymes, which are weakened in many people owing to gene polymorphisms. Here, we produced a high-activity human ADH1B (hADHIB)-expressing probiotic that secreted the hADH1B enzyme to decompose alcohol in the intestinal tract after oral administration. Our results showed that the oral hADHIB-expressing probiotic reduced the absorption of alcohol, prolonged alcohol tolerance time, and shortened the recovery time after drinking. Alongside, fat accumulation in liver and basal structure disorder of small intestine caused by heavy alcohol intake was improved. Therefore, the engineered probiotic has the potential to be prepared as a mate to wine. This study also demonstrated for the first time that alcohol decomposition can be catalyzed by ectopically expressed hADH1B, providing a practical basis for subsequent development of super-biological antidotes that effectively deliver multiple enzymes.

\section{Introduction}

Wine is an indispensable part of human civilization that serves economic, social, medical, and religious purposes. According to the latest statistics, between 1990 and 2017, per capita alcohol consumption by adults increased from $5.9 \mathrm{~L}$ to $6.5 \mathrm{~L}$ worldwide and is forecast to reach $7.6 \mathrm{~L}$ by 2030 [1]. Large-scale population-based cohort studies have found that moderate drinking does not increase the risk of allcause mortality among drinkers [2]. Several studies have shown that moderate drinking of alcohol may offer health benefits, including lowering the incidence of type II diabetes and cardiovascular disease [3-5], and neuroprotective effects $[6,7]$. Binge-drinking, which is characterized by intake of large amounts of alcohol in a short time period, is a major cause of preventable impairment of health. Alcoholic beverages disturb the absorption of nutrients, including several vitamins, sodium, and water, by the intestine [8]. Alcohol consumption also affects the immune system of the gut, contributing to the immune deficiency associated with alcohol abuse [9]. As alcohol enters the bloodstream, the cardiovascular system and liver are the main targets of damage, resulting in heart disease, cardiomyopathy, alcoholic fatty liver disease, hepatitis, cirrhosis, and other alcohol-associated liver disease [10, 11]. Alcohol and its secondary metabolite acetaldehyde directly attack the nervous system, leading to a host of neurological problems including anxiety, insomnia, and loss of memory $[12,13]$. According to the World Health Organization Report on Alcohol and Health (2011), alcohol abuse is responsible for at least 60 major types of systemic diseases and incurs a heavy socioeconomic cost. Given the many different internal and external motivations and social-cognitive reasons for drinking, better compliance may be achieved with the use of anti-alcoholics compared with abstinence from alcohol; thus, this approach may help to mitigate the health problems caused by alcohol intake. 
About $2-10 \%$ of oral alcohol is excreted through breath, urine, and sweat; the remainder is metabolized to acetaldehyde by alcohol dehydrogenase (ADH) and then quickly converted to carbon dioxide and water in a reaction catalyzed by aldehyde dehydrogenase (ALDH) in the liver [14]. Large-scale phenotyping studies have consistently found that the genetic diversity of these two proteases is the main reason for the wide variation in people's tolerance to alcohol [15]. A variant of ADH1B, which occurs primarily in Asian and Polynesian populations, shows higher enzymatic activity. The ALDH2*2 allele (Glu504Lys), which is also common in East Asia, is associated with adverse reactions to alcohol consumption, including facial flushing, hypotension, headaches, and nausea $[15,16]$. Therefore, genetic modification or external supplementation with a highly efficient enzyme may be more useful to alcoholics than drugs or foods intended to increase endogenous catalytic enzyme activity.

In theory, many gene editing techniques, such as the CRISPR/Cas9 system, AAV virus, and lentiviruses, can be used to regulate the expression of genes. Administration of an adenoviral vector containing the hADH1B gene accelerates the breakdown of alcohol in mice [17]. However, owing to safety concerns, these techniques are banned in humans. In the delivery of bioactive molecules, the efficiency of delivery and the maintenance of activity are key limiting factors. In addition, synthetic protein supplements have high requirements for enzyme purity, concentration, and half-life; these standards are difficult to reach and the associated costs are high. Recently, bacterial engineering, which integrates genetic engineering technique with bacterial genomics, has made it possible to lead-in effective biomacromolecules. To date, there have been dozens of clinical studies of the use of bacteria for disease management [18]. These bacteria include Escherichia coli and Bacteroides, which predominate in the gastrointestinal tract. The bacteria used in such studies are modified so that they not produce virulence factors and are thus unable to induce damage to the surface of the intestinal epithelium $[19,20]$. Certain anaerobic bacteria including Salmonella can be targeted to tumors and can therefore be engineered as anti-tumor biological agents [21-23]. Owing to the chemotaxis ability, biomolecule secretion, and other specific biological characteristics of these bacteria, their use, combined with a variety of gene editing techniques, has greatly expanded the scope of biotherapy [24] .

Lactococcus lactis, a probiotic, is a non-pathogenic, non-colonizing, food-grade bacterial strain that is commonly used in the dairy industry and has an excellent safety record. Genetically modified L. lactis can serve as a vehicle for delivery of biologically active molecules $[25,26]$. In this study, the hADH1B gene was inserted into a pNZ8149 construct equipped with a Gap-A promoter, and L. lactis was chosen as the delivery medium for ectopic expression of hADH1B. The results showed that our recombinant $L$. lactis could reduce the absorption of ethanol and improve alcohol tolerance, prolonging the alcohol tolerance time and shortening the recovery time after drinking. Further investigation showed that the intestinal inflammation and acute liver damage caused by binge-drinking were both improved. These findings suggest that our recombinant probiotic has potential clinical applications as an efficacious means of alleviating alcohol-related health problems.

\section{Materials And Methods}




\section{Cloning and expression of recombinant hADH gene}

The plasmid pNZ8149 (Cat\# VS-ELV00300-01) equipped with a high-efficiency constitutive promoter (GapA promoter, patented CN111518801A) was chosen as the vector structure (Fig. 1A). The human ADH1B gene (GenBank Accession No. NM_000668) was cloned into multiple cloning sites, and its Nterminal was fused with the Usp45-LESS-EK sequence. The expressing DNA constructor was transformed into L. lactis cremoris NZ3900 (Cat\# VS-ELS03900-01) by electrotrans formation, and Elliker agar plates were used to screen recombinant probiotics. The electrotransformation conditions were $2000 \mathrm{~V}, 25 \mu \mathrm{F}$, and $200 \Omega$. Recombinant probiotics were identified by PCR using forward (5'-

CATGCCATGGTCATGAAAAAAAAGATTATCTCAGCT-3') and reverse (5'GCTCTAGATCAAAACGTCAGGACGGTACG-3') primers and sequenced. The recombinant probiotics were resuspended (1\%) in M17 fluid medium, incubated at $30^{\circ} \mathrm{C}$ for $8 \mathrm{~h}$ and centrifuged (4000 $\mathrm{g}$ for $10 \mathrm{~min}$ at $4{ }^{\circ} \mathrm{C}$ ), and the supernatant was collected. Then, proteins in the supernatant were precipitated by a lowtemperature ethanol precipitation method [27]. Equal amounts of protein samples were distributed in $10 \%$ sodium dodecyl sulfate polyacrylamide gels; after separation, proteins were transferred to a polyvinylidene fluoride membrane, incubated with blocking buffer ( $5 \%$ fat-free milk) for $1 \mathrm{~h}$ at room temperature, and blotted with anti-hADH antibody (Santa Cruz). The membrane was then incubated with horseradish peroxidase-conjugated secondary antibodies for $1 \mathrm{~h}$ at room temperature. Signals were visualized using a Mini ChemiTM 580 (Sage Creation Science Co., Beijing, China) with Super Signal West Pico Chemiluminescent Substrate (Pierce, Rockford, IL, USA).

\section{Microcapsulation of recombinant probiotics and acid resistance test}

After 6-8 hours culture, the recombinant probiotics were centrifuged ( $4000 \mathrm{~g}$ for 10 min at $4{ }^{\circ} \mathrm{C}$ ) and collected. The recombinant probiotics were suspended in $3 \%(\mathrm{w} / \mathrm{v})$ sodium alginate solution. The suspension was dropped into soybean oil (containing $0.2 \%$ Tween-80) at a ratio of $1: 5$, followed by stirring for $10 \mathrm{~min}$ with a magnetic mixer at $600 \mathrm{rpm}$. Then, $0.05 \mathrm{M} \mathrm{CaCl}_{2}$ solution was added slowly with stirring (600 rpm for $10 \mathrm{~min}$ ). After centrifugation ( $350 \mathrm{~g}$ for $10 \mathrm{~min}$ at $4{ }^{\circ} \mathrm{C}$ ), the microcapsulation was collected, added to the lyoprotectant (19.5\% maltodextrin and $2.5 \%$ skim milk powder), resuspended, transferred to a Petri dish, kept at $-80^{\circ} \mathrm{C}$ until completely frozen, and then transferred to a vacuum freezedryer to obtain freeze-dried recombinant probiotic microcapsules. The recombinant probiotic microcapsules were dissolved in artificial gastric acid $(0.2 \% \mathrm{NaCl}, \mathrm{pH} 1.2)$ at stationary state for $2 \mathrm{~h}$. The recombinant probiotics were released with the broken fluid (19:81 ratio of $0.2 \mathrm{M} \mathrm{NaH}_{2} \mathrm{PO}_{4}$ to $0.2 \mathrm{M}$ $\mathrm{Na}_{2} \mathrm{HPO}_{4}$ ) at $200 \mathrm{rpm}$ for $30 \mathrm{~min}$ at $37^{\circ} \mathrm{C}$, and the effects of microcapsulation were verified by a plate count method.

\section{Animal studies}

All animal studies were approved by the Institutional Animal Care and Use Committee of the Institute of Zoology, Chinese Academy of Sciences. Six-week-old C57BL/6J mice were purchased from Vital River Laboratory Animal Technology Co. and were housed in our specific-pathogen-free laboratory animal 
house (Institute of Zoology of Beijing, Chinese Academy of Sciences, China) at room temperature $\left(24^{\circ} \mathrm{C}\right)$ with a 12-h light/dark cycle; for all experiments, five mice were housed in each cage and had free access to water. The diet was composed of $11.7 \% \mathrm{kcal}$ from fat, $66.1 \% \mathrm{kcal}$ from carbohydrates, and $22.2 \%$ kcal from protein (MD17121, Medicience).

\section{Detection of mouse intoxication}

Red Start (Hongxing) Erguotou (fen-flavor liquor, $56 \%$ vol) purchased from a supermarket was chosen for use in the mouse binge-drinking model. To establish a safe and stable model of acute drunkenness, 9week-old male C57BL/6J mice weighing 20-22 g were randomly divided into three groups ( $\mathrm{n}=5$ in each group), and $4 \mathrm{mg} / \mathrm{g} \mathrm{BW}, 6 \mathrm{mg} / \mathrm{g}$ BW, $8 \mathrm{mg} / \mathrm{g} \mathrm{BW}$ was given, respectively. Righting reflex was used as the criterion to determine drunkenness. Briefly, the mouse's back was placed on the ground with its abdomen and limbs facing upward. If the mouse could not turn itself over within $30 \mathrm{~s}$, it was considered to have lost its normal righting reflex [28]. The time point at which the righting reflex was lost was defined as the drunkenness point, and the duration between the first drink and drunkenness was taken as the alcohol tolerance time. The alcohol tolerance times for the three groups of mice were all shorter than $20 \mathrm{~min}$, so mice that did not lose their righting reflex within $1 \mathrm{~h}$ were considered not to show acute drunkenness. Considering the drunkenness rate and safety, a dosage of $6 \mathrm{mg} / \mathrm{g}$ BW was chosen for subsequent experiments. In the intestinal environment, the peak expression of recombinant probiotics secreting foreign proteins occurred at about $1-2 \mathrm{~h}^{[29,30]}$. L. lactis $\left(1 \times 10^{9} \mathrm{CFU}\right)$ expressing hADH1B was administered to enable detection of the anti-inebriation effects of the oral recombinant probiotics $(n=8)$. $L$. lactis containing the pNZ construct was used as a control $(\mathrm{n}=8)$. After $1 \mathrm{~h}$, all mice were given $6 \mathrm{mg} / \mathrm{g}$ BW alcohol, and the alcohol tolerance time was recorded.

\section{Motor recovery monitoring}

One hour after alcohol administration, the mice were placed individually in motion detection systems to detect their movements every $15 \mathrm{~s}$. The machine read 0 when the mice were drunk. When the number of movements at four consecutive recorded time points was non-zero, the mice were considered to have recovered their motor ability.

\section{Histological analysis}

For hematoxylin and eosin (H\&E) staining, tissues fixed with 4\% paraformaldehyde were embedded in paraffin, and 5 - $\mu \mathrm{m}$-thick sections were stained and observed under a 10X or 20X objective lens.

\section{Statistical analysis}

For the drunkenness experiment, eight mice in each group were studied. Data are expressed as mean \pm standard error of the mean. Statistically significant differences between two groups were determined using a two-tailed student's t-test. Statistical significance was defined as $p<0.05\left({ }^{*} p<0.05,{ }^{* *} p<0.01\right.$, $\star \star \star p<0.001)$. All statistical analyses were performed using GraphPad Prism 8 software. 


\section{Results}

\section{Preparation and characterization of oral recombinant probiotics}

pNZ8149 is a widely used probiotic expression vector, and new constructs equipped with the GapA promoter (CN111518801A) have proved to be highly effective in driven foreign genes expression. To produce hADH1B-secreting recombinant probiotics, the gene was inserted into a pNZ8149-GapA construct and transferred into $L$. lactis by electrotransfer technology. An enteric capsule was used to protect the $L$. lactis from being killed by stomach fluids. In theory, hADH1B would be secreted in the intestine and transported into the blood (Fig. 1A). The DNA construct containing the target gene was detected by PCR (Fig. 1B) and further identified by sequencing. In our new DNA construct, the intrinsic nisin promoter was changed to the GapA promoter, followed by a secretory peptide editing sequence (Usp45), an expression enhancement element (LESS), and an enterokinase-cutting peptide editing sequence (EK). To confirm that the construct still worked as expected to produce free protease, western blotting was conducted; the results showed that the recombinant $L$. lactis could specifically secrete hADH1B into the culture supernatant (Fig. 1C). Further, the hADH1B-expressing L. lactis was prepared in micro-capsule particles, as this dosage form could protect it from bacterial activity (Fig. 1D) as well as enabling easier operation for subsequent oral experiments in mice.

\section{Oral recombinant probiotics prolonged alcohol tolerance time}

To construct a safe and stable model of acute drunkenness, a volume gradient of wine were given to mice, and $6 \mathrm{mg} / \mathrm{g}$ BW was chosen for subsequent experiments, as this dosage caused loss of exercise ability in all mice within 1 hour after drinking without being life-threatening (Supplementary table 1). In the intestinal environment, the recombinant probiotics secreting foreign proteins reached its peak at about $1-2 \mathrm{~h}[29,30]$. 1 hour after of $1 \times 10^{9} \mathrm{CFU}$ pNZ control bacteria or hADH1B expressing bacteria gavage, the mice were given $6 \mathrm{mg} / \mathrm{g} \mathrm{BW}$ alcohol. The results showed that the alcohol tolerance time (i.e., the time from drinking to loss of exercise ability) was significantly prolonged in mice treated with the hADH1B-expressing probiotic (Supplementary table 2, Fig. 2). All mice in the pNZ group lost their selfrighting reflex within $1200 \mathrm{~s}$, whereas nearly half of the mice in the hADH1B-expressing probiotic group were still able to move $1 \mathrm{~h}$ after drinking (Supplementary table 3 ). In conclusion, the hADH1B-expressing probiotic effectively enhanced acute alcohol tolerance and increased the alcohol intake threshold for acute intoxication.

\section{Oral probiotics reduced exercise recovery time in drunken mice}

It takes 6-10 h for drunk mice to recover. To enable accurate recording of the recovery times of mice in different treatment groups, mice were placed into the exercise recorder $1 \mathrm{~h}$ after drinking. Exercise times were recorded every $15 \mathrm{~s}$ (Fig. 3A). When the recorder received non-zero data four consecutive times, the mice were considered to have recovered their locomotor ability. Statistically, we found that mice treated with $\mathrm{hADH1B}$ regained exercise capacity after $(5.5 \pm 0.41, \mathrm{n}=6)$, significantly shorter than the time taken in the pNZ probiotic treatment group $(6.4 \pm 0.41, n=7)$, and one-quarter of the mice in the hADH1B- 
expressing probiotic treatment group exercised throughout the whole process (Fig. 3B and Supplementary table 4). These results indicate that hADH1B expression of probiotics could shorten the recovery time of drunk mice.

\section{Oral probiotics attenuate hepato-intestinal lesions associated with acute alcohol consumption.}

Alcohol is absorbed mostly in the gut and eventually transported to the liver, where it is decomposed. Therefore, the gut-liver axis has an important role in regulating ethanol metabolism, and the intestine and liver are also the organs most directly damaged after drinking $[9,31]$. To detect acute intoxication in two groups of mice, the mucosal lesions of the intestine were observed. The goblet cells in pNZ-treated drunken mice showed much more hypertrophy than those of the non-drunken mice, and hADH1Bexpressing probiotics treatment mitigated the pathogenic effects of acute alcohol consumption (Fig. 4C), indicating a reduction in alcohol absorption through the gut. Alcohol in the blood of mice reached its peak level 2-3 $\mathrm{h}$ after drinking. To test the effects of different probiotics on alcohol absorption, blood alcohol levels were measured at different points after drinking using an EnzyChrom ${ }^{\text {TM }}$ Ethanol Assay Kit (BioAssay Systems, ECET-100). In the first hour, the alcohol content in the blood of mice in both groups showed no difference in. Two hours after drinking, the serum alcohol residue in the pNZ group continued to increase, whereas that in the hADH group showed a significant downward trend and was significantly lower than that in the pNZ group (Fig. 4A). On further examination, we found that hADH1B treatment reduced blood triglyceride concentrations (Fig. 4B) and, synchronously, reduced lipid levels in the livers of mice treated with hADH1B (Fig. 4D). In conclusion, treatment with hADH1B-expressing probiotics can alleviate intestinal damage caused by acute alcohol consumption and reduce fat content in the liver and blood.

\section{Discussion}

Recently, social diversity and improvements in living standards have led to an increase in the frequency of drinking, which is likely to affect people's health [32]. The immediate phenomenon after drinking is hangover, the most common symptoms of which include tiredness, increased thirst, sleepiness, headache, dry mouth, and nausea [33]. These symptoms can adversely affect an individual's work effectiveness and daily activities, as well as having negative economic consequences [34]. Therefore, the search for and development of effective anti-alcohol products is receiving increasing attention.

Approximately $90 \%$ of ethanol metabolism occurs in the liver, that is, ADH metabolizes ethanol to acetaldehyde and then ALDH metabolizes acetaldehyde to acetate [35]. Therefore, the rapid and effective removal of excess ethanol and its metabolite acetaldehyde has an important role in preventing liver damage [36]. The various anti-alcoholic products that have been researched mainly activate ADH and ALDH to relieve hangover and protect the body. For example, egg white, green tea, fenugreek seeds, and coconut water can enhance ADH activity to varying degrees [37,38]. Rosiglitazone also can activate ADH and ALDH to alleviate hangover [39]. However, some researchers have suggested that the main factors that affect an individual's degree of hangover are genetic [40]. There is evidence that individuals with the ALDH2*2 allele are highly deficient in ethanol decomposition [41]. It has been suggested that Korean pear 
juice can stimulate ADH and ALDH to reduce alcohol levels [42], but no significant sobering effect was found in individuals with the ALDH mutant genotype [43]. Moreover, alcohol metabolism can increase oxidative stress in the body [44]; therefore, substances with high antioxidant activity, such as Asparagus officinalis [45] and red ginseng [46], have been proposed as candidate anti-alcohol products. However, other studies have found that such products do not alleviate the negative effects of alcoholism [38]. At present, there are some unanswered questions related to screening for effective anti-alcohol products. (I) What are the mechanisms by which these products activate ADH and ALDH? (II) How effective are they in individuals with genetic mutations? (III) How can we rapidly search for and develop effective, easy to eat products with low manufacturing costs and high efficiency of industrial production?

In the current study, we used safe food-grade probiotic L. lactis to recombine and express human ADH in vitro (Fig. 1). The safety and efficacy of the L. lactis oral system has been demonstrated previously [29]. The gastrointestinal tract is the most heavily burdened of all tissues after alcohol consumption [47], and hypertrophy of intestinal goblet cells is induced by alcohol stimulation [48]. We found that hypertrophy of intestinal goblet cells was improved in the hADH1B-treated group, indicating that the L. lactis oral system directly reduced the intestinal effects of alcohol (Fig. 4C). It is likely that the recombinant probiotics expressed active hADH1B after passing into the intestinal tract and directly decomposed alcohol there, thus reducing the burden on the intestinal tract. The observed reduction in blood ethanol levels in the hADH1B treatment group also supports this view (Fig. 4A). In addition, after ethanol enters the bloodstream, lipin-1 is upregulated; this leads to accumulation of cytosolic lipin-1 protein, increases PAP activity, and promotes the synthesis of triglycerides in the liver [49-52]. Therefore, reducing the amount of alcohol in the bloodstream could prevent the accumulation of lipids in the liver. Unlike other hangover products, recombinant probiotics expressing hADH1B could directly reduce the amount of ethanol entering the blood, thus achieving the effect of liver protection (Fig. 4B, D), suggesting that recombinant probiotics expressing hADH1B has the potential to prevent and treat alcoholic fatty liver disease.

In conclusion, we found that recombinant probiotics could express hADH directly in the intestinal tract, decompose ethanol in the body in a short time, and effectively reduce the negative effects on various organs. Most important, we make up the inability of individuals with ADH and ALDH genetic mutations to effectively decompose ethanol. Moreover, the recombinant probiotics are safe and easy to use, and have a mature industrial production system and low production costs. The present research not only provides new strategies for treatment and prevention of the negative effects of alcohol, it also has the potential for widespread application.

\section{Declarations}

\section{Authors' contributions}

Conceived and designed the experiments: X.J., C.Y., W.J., G.S., M.D and X.M.; Performed the experiments: X.J., C.Y., S.Y., H.Z., R.Y., H.Z., L.C., R.J., K.Z. and Y.H.; Analyzed the data: X.J., C.Y., W.J. and X.M.; Wrote 
the paper: X.J. and C.Y.; Edited the manuscript: X.J., C.Y., S.Y., H.Z., R.Y., H.Z., L.C., R.J., K.Z. and Y.H.; All authors read and approved the final manuscript.

Ethics approval and consent to participate

Not applicable

\section{Consent for publication}

Not applicable

\section{Availability of data and materials}

All data generated or analyzed during this study are included in this published article. The datasets used and/or analyzed during the current study are available from the corresponding author on reasonable request.

\section{Conflict of interest statement}

The authors declare no competing interests.

\section{Acknowledgements}

Not applicable

\section{Funding}

This work was supported by the General Program (Major Research Plan) of the National Natural Science Foundation of China (92057208), the National Key Research and Development Program of China (2017YFC1001003), the National Natural Science Foundation of China (81770834), (81770577), (82170591), the Xin Xiang Medical University (XYBSKYZZ202135) and the Science and technology innovation talent Program of Henan Province (19HASTIT015).

\section{References}

1. Manthey J, Shield KD, Rylett M, Hasan OSM, Probst C, Rehm J: Global alcohol exposure between 1990 and 2017 and forecasts until 2030: a modelling study. Lancet 2019, 393:2493-2502.

2. Marugame T, Yamamoto S, Yoshimi I, Sobue T, Inoue M, Tsugane S, Japan Public Health Centerbased Prospective Study G: Patterns of alcohol drinking and all-cause mortality: results from a largescale population-based cohort study in Japan. Am J Epidemiol 2007, 165:1039-1046.

3. Baer DJ, Judd JT, Clevidence BA, Muesing RA, Campbell WS, Brown ED, Taylor PR: Moderate alcohol consumption lowers risk factors for cardiovascular disease in postmenopausal women fed a controlled diet. Am J Clin Nutr 2002, 75:593-599. 
4. Conigrave KM, Hu BF, Camargo CA, Jr., Stampfer MJ, Willett WC, Rimm EB: A prospective study of drinking patterns in relation to risk of type 2 diabetes among men. Diabetes 2001, 50:2390-2395.

5. Koppes LL, Dekker JM, Hendriks HF, Bouter LM, Heine RJ: Moderate alcohol consumption lowers the risk of type 2 diabetes: a meta-analysis of prospective observational studies. Diabetes Care 2005, 28:719-725.

6. Peng C, Li WA, Fu P, Chakraborty T, Hussain M, Guthikonda M, Rafols JA, Ding Y: At low doses ethanol maintains blood-brain barrier (BBB) integrity after hypoxia and reoxygenation: a brain slice study. Neurol Res 2013, 35:790-797.

7. Zeng X, Asmaro K, Ren C, Gao M, Peng C, Ding JY, Fredrickson V, Ji X, Ding Y: Acute ethanol treatment reduces blood-brain barrier dysfunction following ischemia/reperfusion injury. Brain Res 2012, 1437:127-133.

8. Bode C, Bode JC: Effect of alcohol consumption on the gut. Best Practice \& Research Clinical Gastroenterology 2003, 17:575-592.

9. Rocco A, Compare D, Angrisani D, Sanduzzi Zamparelli M, Nardone G: Alcoholic disease: liver and beyond. World J Gastroenterol 2014, 20:14652-14659.

10. Uyarel $\mathrm{H}$, Ozdol C, Gencer AM, Okmen E, Cam N: Acute alcohol intake and QT dispersion in healthy subjects. J Stud Alcohol 2005, 66:555-558.

11. Krystal JH, Staley J, Mason G, Petrakis IL, Kaufman J, Harris RA, Gelernter J, Lappalainen J: Gamma-aminobutyric acid type A receptors and alcoholism: intoxication, dependence, vulnerability, and treatment. Arch Gen Psychiatry 2006, 63:957-968.

12. Krystal JH, Staley J, Mason G, Petrakis IL, Kaufman J, Harris RA, Gelernter J, Lappalainen J: gamma-Aminobutyric acid type A receptors and alcoholism - Intoxication, dependence, vulnerability, and treatment. Archives of General Psychiatry 2006, 63:957-968.

13. Enoch MA, Schwartz L, Albaugh B, Virkkunen M, Goldman D: Dimensional anxiety mediates linkage of GABRA2 haplotypes with alcoholism. American Journal of Medical Genetics Part BNeuropsychiatric Genetics 2006, 141b:599-607.

14. Schuckit MA: Alcohol-use disorders. Lancet 2009, 373:492-501.

15. Morozova TV, Mackay TFC, Anholt RRH: Genetics and genomics of alcohol sensitivity. Molecular Genetics and Genomics 2014, 289:253-269.

16. Edenberg HJ: The genetics of alcohol metabolism: role of alcohol dehydrogenase and aldehyde dehydrogenase variants. Alcohol Res Health 2007, 30:5-13. 
17. Rivera-Meza M, Quintanilla ME, Tampier L: Reduction of ethanol consumption in alcoholpreferring rats by dual expression gene transfer. Alcohol Alcoho/ 2012, 47:102-108.

18. Li SQ, Jiang WQ, Zheng CX, Shao D, Liu YL, Huang SQ, Han J, Ding JX, Tao Y, Li MQ: Oral delivery of bacteria: Basic principles and biomedical applications. Journal of Controlled Release 2020, 327:801-833.

19. Tenaillon O, Skurnik D, Picard B, Denamur E: The population genetics of commensal Escherichia coli. Nature Reviews Microbiology 2010, 8:207-217.

20. Rashidan M, Azimirad M, Alebouyeh M, Ghobakhlou M, Aghdaei HA, Zali MR: Detection of B. fragilis group and diversity of bft enterotoxin and antibiotic resistance markers cepA, cfiA and nim among intestinal Bacteroides fragilis strains in patients with inflammatory bowel disease. Anaerobe 2018, 50:93100.

21. Lee $\mathrm{CH}, \mathrm{Wu} \mathrm{CL}$, Shiau AL: Systemic administration of attenuated Salmonella choleraesuis carrying thrombospondin-1 gene leads to tumor-specific transgene expression, delayed tumor growth and prolonged survival in the murine melanoma model. Cancer Gene Therapy 2005, 12:175-184.

22. Felgner S, Kocijancic D, Pawar V, Weiss S: Biomimetic Salmonella: A Next-Generation Therapeutic Vector? Trends in Microbiology 2016, 24:850-852.

23. Pawelek JM, Low KB, Bermudes D: Tumor-targeted Salmonella as a novel anticancer vector. Cancer Research 1997, 57:4537-4544.

24. Ozdemir T, Fedorec AJH, Danino T, Barnes CP: Synthetic Biology and Engineered Live Biotherapeutics: Toward Increasing System Complexity. Cell Syst 2018, 7:5-16.

25. Steidler L, Hans W, Schotte L, Neirynck S, Obermeier F, Falk W, Fiers W, Remaut E: Treatment of murine colitis by Lactococcus lactis secreting interleukin-10. Science 2000, 289:1352-1355.

26. Braat H, Rottiers P, Hommes DW, Huyghebaert N, Remaut E, Remon JP, van Deventer SJ, Neirynck S, Peppelenbosch MP, Steidler L: A phase I trial with transgenic bacteria expressing interleukin-10 in Crohn's disease. Clin Gastroenterol Hepatol 2006, 4:754-759.

27. Mattice KD, Marangoni AG: Functionalizing zein through antisolvent precipitation from ethanol or aetic acid. Food Chem 2020, 313:126127.

28. Gao S, Calderon DP: Robust alternative to the righting reflex to assess arousal in rodents. Sci Rep 2020, 10:20280.

29. Yuan S, Dong M, Zhang H, Xu H, Wang Q, Yan C, Ye R, Jiang X, Zhou H, Chen L, et al: Oral delivery of a Lactococcus lactis expressing extracellular TGFbetaR2 alleviates hepatic fibrosis. App/ Microbiol Biotechnol 2021. 
30. Cao WY, Dong M, Hu ZY, Wu J, Li YC, Xu HD: Recombinant Lactococcus lactis NZ3900 expressing bioactive human FGF21 reduced body weight of Db/Db mice through the activity of brown adipose tissue. Benef Microbes 2020, 11:67-78.

31. Rajendram R, Preedy VR: Effect of alcohol consumption on the gut. Dig Dis 2005, 23:214-221.

32. Jung S, Lee SH, Song YS, Lee SY, Kim SY, Ko KS: Effect of Beverage Containing Fermented Akebia quinata Extracts on Alcoholic Hangover. Prev Nutr Food Sci 2016, 21:9-13.

33. Penning R, McKinney A, Verster JC: Alcohol hangover symptoms and their contribution to the overall hangover severity. Alcohol Alcohol 2012, 47:248-252.

34. Frone MR, Verster JC: Alcohol hangover and the workplace: a need for research. Curr Drug Abuse Rev 2013, 6:177-179.

35. Bourogaa E, Nciri R, Mezghani-Jarraya R, Racaud-Sultan C, Damak M, El Feki A: Antioxidant activity and hepatoprotective potential of Hammada scoparia against ethanol-induced liver injury in rats. J Physiol Biochem 2013, 69:227-237.

36. Eriksson CJ: The role of acetaldehyde in the actions of alcohol (update 2000). Alcohol Clin Exp Res 2001, 25:15S-32S.

37. Wang F, Zhang YJ, Zhou Y, Li Y, Zhou T, Zheng J, Zhang JJ, Li S, Xu DP, Li HB: Effects of Beverages on Alcohol Metabolism: Potential Health Benefits and Harmful Impacts. Int J Mol Sci 2016, 17:354.

38. Srinivasan S, Dubey KK, Singhal RS: Influence of food commodities on hangover based on alcohol dehydrogenase and aldehyde dehydrogenase activities. Curr Res Food Sci 2019, 1:8-16.

39. Jung TW, Lee JY, Shim WS, Kang ES, Kim SK, Ahn CW, Lee HC, Cha BS: Rosiglitazone relieves acute ethanol-induced hangover in Sprague-Dawley rats. Alcohol Alcohol 2006, 41:231-235.

40. Slutske WS, Piasecki TM, Nathanson L, Statham DJ, Martin NG: Genetic influences on alcoholrelated hangover. Addiction 2014, 109:2027-2034.

41. Park YM, Won JH, Kim YH, Choi JW, Park HJ, Lee KT: In vivo and in vitro anti-inflammatory and anti-nociceptive effects of the methanol extract of Inonotus obliquus. J Ethnopharmaco/ 2005, 101:120128.

42. Lee HS, Isse T, Kawamoto T, Woo HS, Kim AK, Park JY, Yang M: Effects and action mechanisms of Korean pear (Pyrus pyrifolia cv. Shingo) on alcohol detoxification. Phytother Res 2012, 26:1753-1758.

43. Lee HS, Isse T, Kawamoto T, Baik HW, Park JY, Yang M: Effect of Korean pear (Pyruspyrifolia cv. Shingo) juice on hangover severity following alcohol consumption. Food Chem Toxicol 2013, 58:101-106. 
44. Masalkar PD, Abhang SA: Oxidative stress and antioxidant status in patients with alcoholic liver disease. Clin Chim Acta 2005, 355:61-65.

45. Kim BY, Cui ZG, Lee SR, Kim SJ, Kang HK, Lee YK, Park DB: Effects of Asparagus officinalis extracts on liver cell toxicity and ethanol metabolism. J Food Sci 2009, 74:H204-208.

46. Lee MH, Kwak JH, Jeon G, Lee JW, Seo JH, Lee HS, Lee JH: Red ginseng relieves the effects of alcohol consumption and hangover symptoms in healthy men: a randomized crossover study. Food Funct 2014, 5:528-534.

47. Molina PE, Nelson S: Binge Drinking's Effects on the Body. Alcohol Res 2018, 39:99-109.

48. Lamas-Paz A, Moran L, Peng J, Salinas B, Lopez-Alcantara N, Sydor S, Vilchez-Vargas R, Asensio I, Hao F, Zheng K, et al: Intestinal Epithelial Cell-Derived Extracellular Vesicles Modulate Hepatic Injury via the Gut-Liver Axis During Acute Alcohol Injury. Front Pharmacol 2020, 11:603771.

49. Hu M, Wang F, Li X, Rogers CQ, Liang X, Finck BN, Mitra MS, Zhang R, Mitchell DA, You M: Regulation of hepatic lipin-1 by ethanol: role of AMP-activated protein kinase/sterol regulatory elementbinding protein 1 signaling in mice. Hepatology 2012, 55:437-446.

50. Shen Z, Liang X, Rogers CQ, Rideout D, You M: Involvement of adiponectin-SIRT1-AMPK signaling in the protective action of rosiglitazone against alcoholic fatty liver in mice. Am J Physiol Gastrointest Liver Physiol 2010, 298:G364-374.

51. Everitt H, Hu M, Ajmo JM, Rogers CQ, Liang X, Zhang R, Yin H, Choi A, Bennett ES, You M: Ethanol administration exacerbates the abnormalities in hepatic lipid oxidation in genetically obese mice. $\mathrm{Am} \mathrm{J}$ Physiol Gastrointest Liver Physiol 2013, 304:G38-47.

52. Jiang Z, Zhou J, Zhou D, Zhu Z, Sun L, Nanji AA: The adiponectin-SIRT1-AMPK pathway in alcoholic fatty liver disease in the rat. Alcohol Clin Exp Res 2015, 39:424-433.

Figures 
A

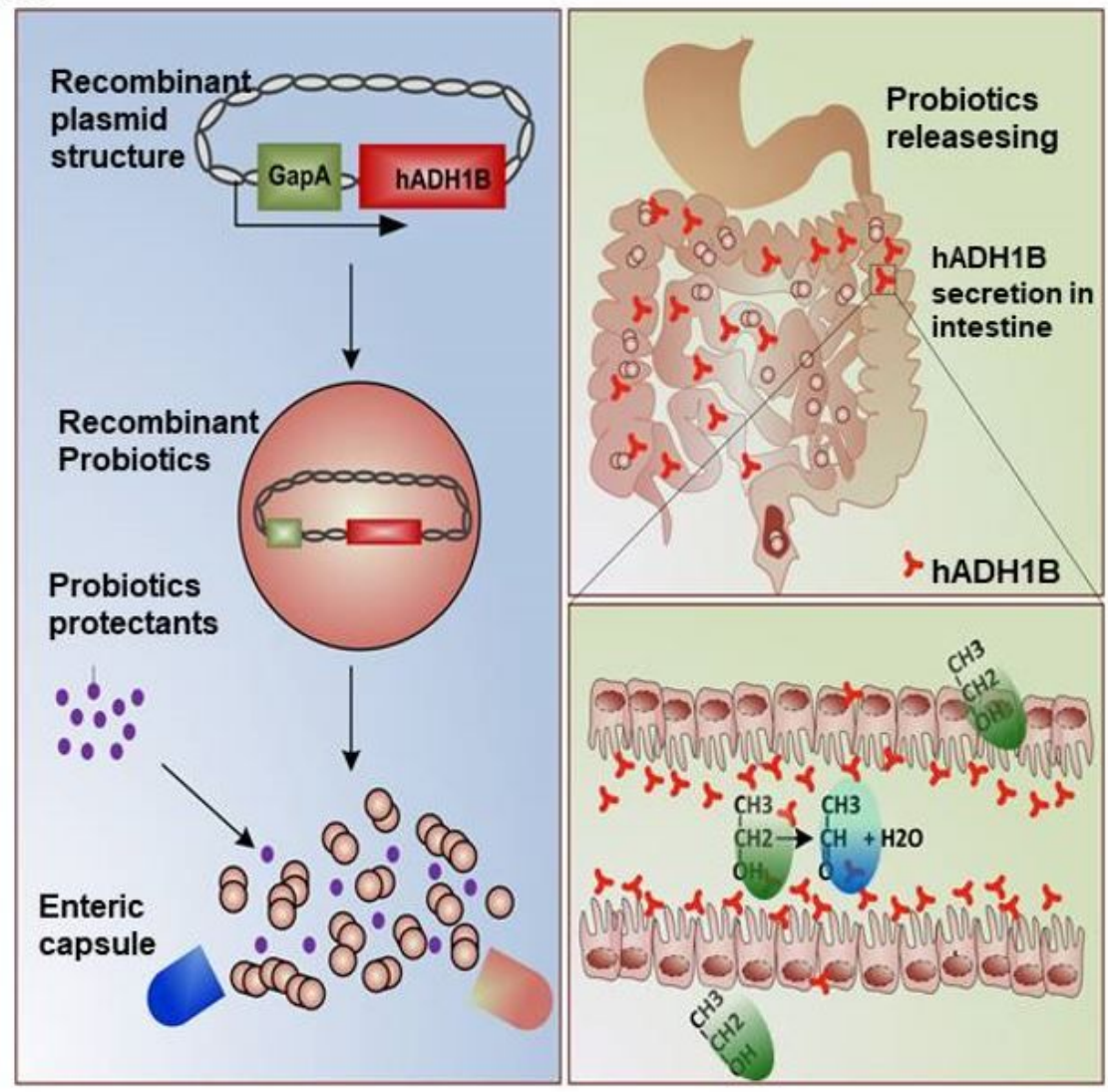

B

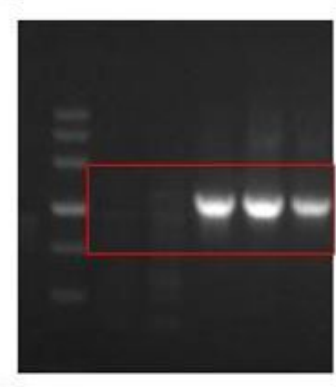

C pNZ hADH1B

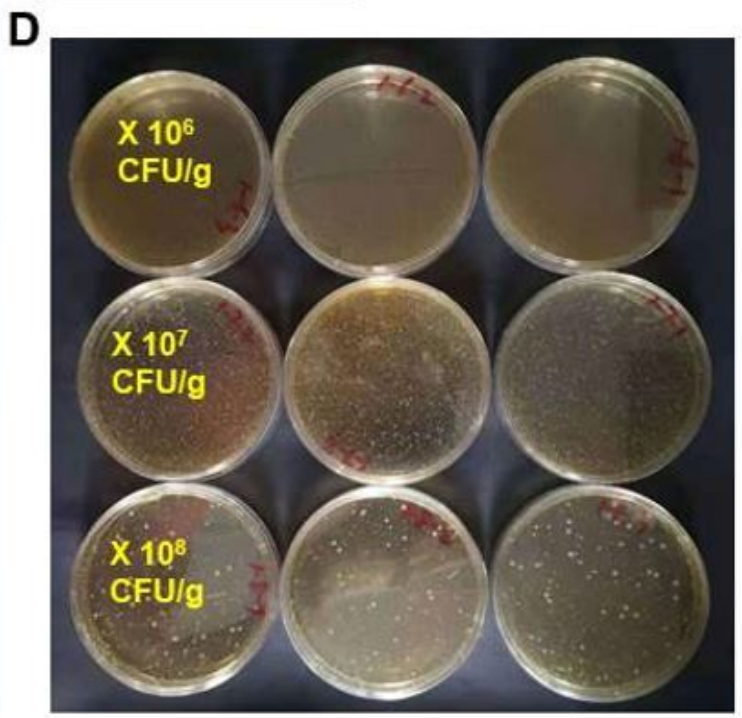

\section{Figure 1}

Preparation and characterization of oral recombinant probiotics for treatment of alcoholics. A. Schematic overview of preparation and function of recombination probiotics. B. PCR identification of hADH1B recombinant probiotics. The target DNA fragment was about 1200 base pairs. C. Immunoblots of culture supernatant to detect the secretion of hADH1B. D. Detection of the viability of encapsulated probiotics. The final concentration of viable bacteria in the ingredients was about $4 \times 109 \mathrm{CFU} / \mathrm{mg}$. 


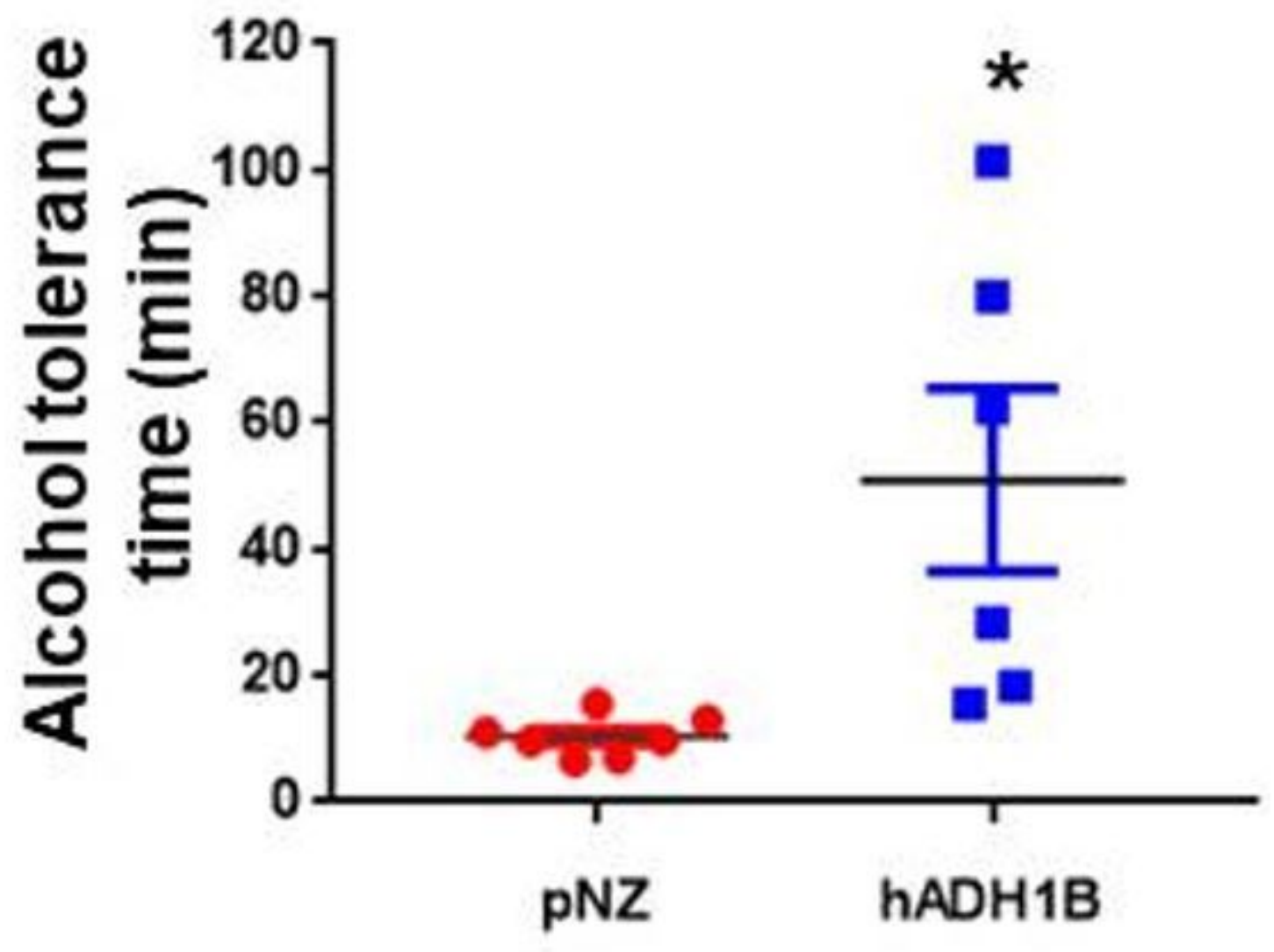

Figure 2

A. Statistical analysis of the differences in alcohol tolerance times between the two groups. hADH1Bexpressing probiotics prolonged alcohol tolerance times. 


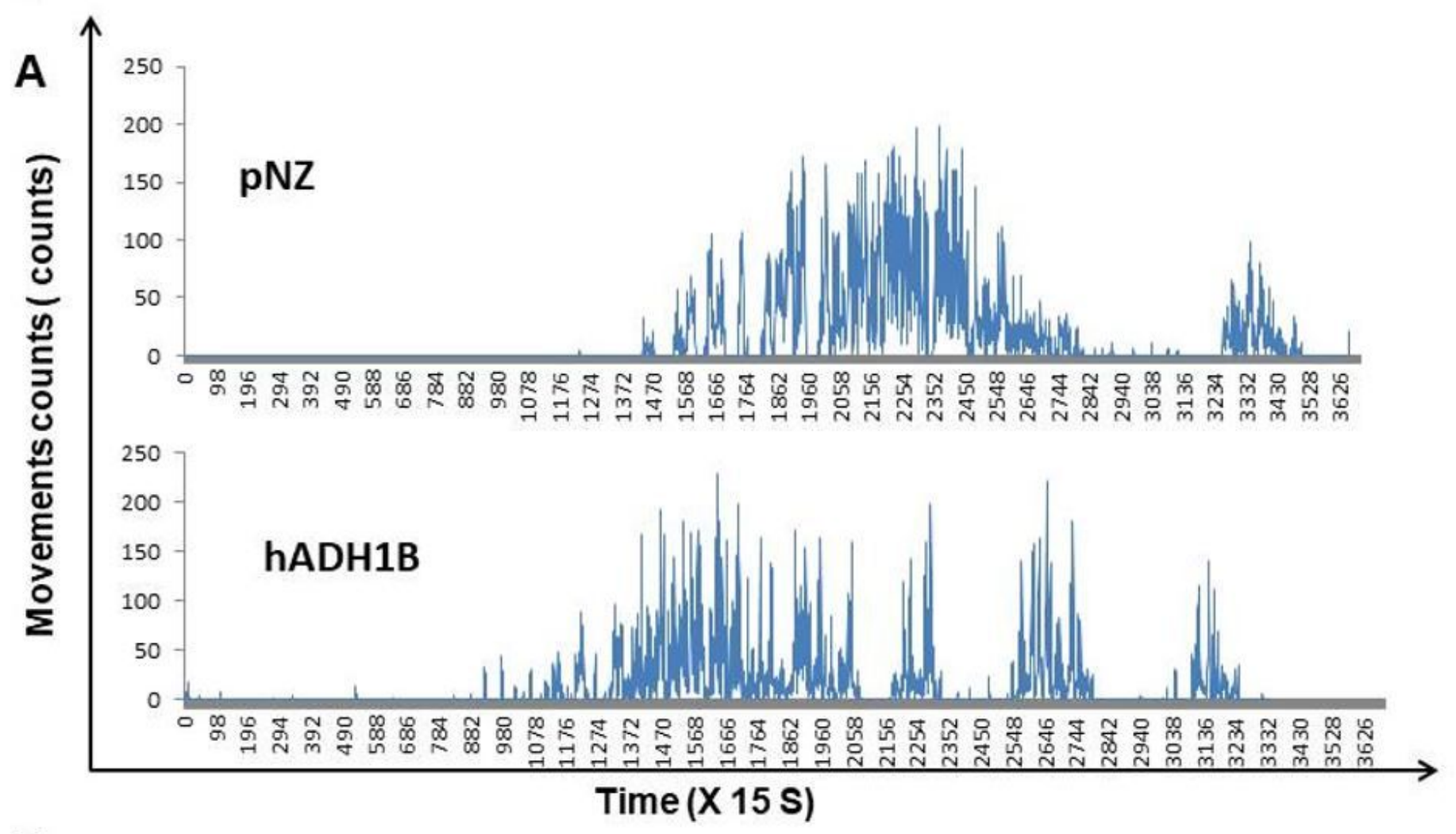

B

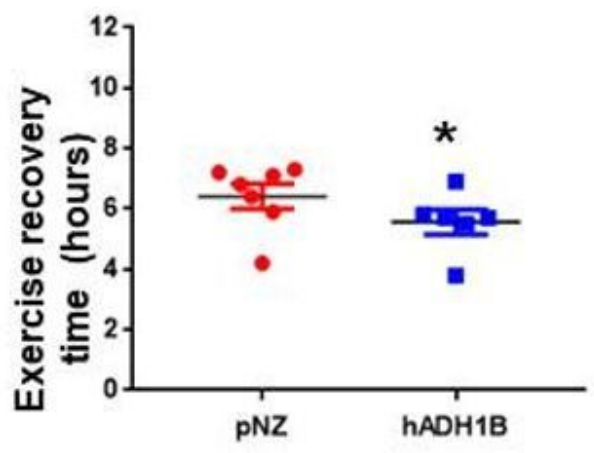

Figure 3

Oral probiotics reduced exercise recovery time in drunken mice. A. Chart showing recording recovery of movement in a drunken mouse. B. hADH1B recombinant probiotics shortened the motor recovery times of drunken mice. 


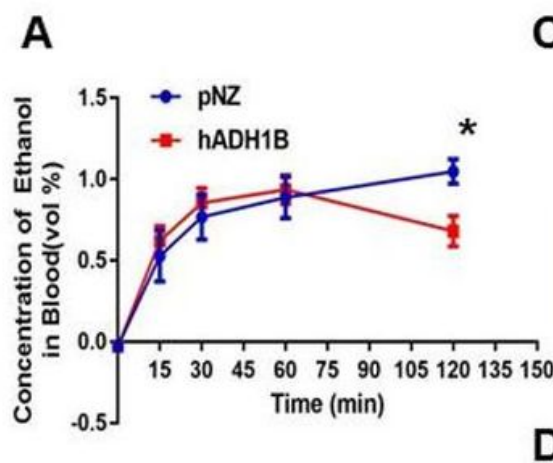

B

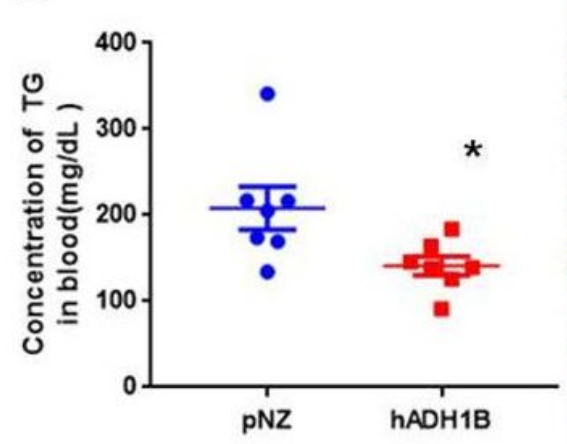

C

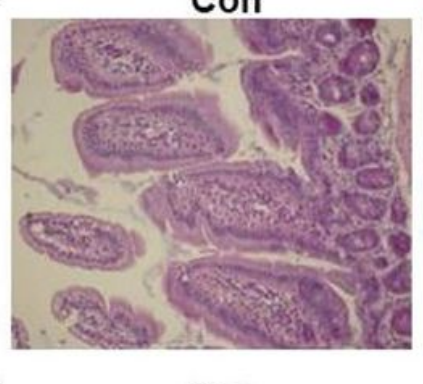

D

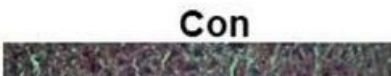

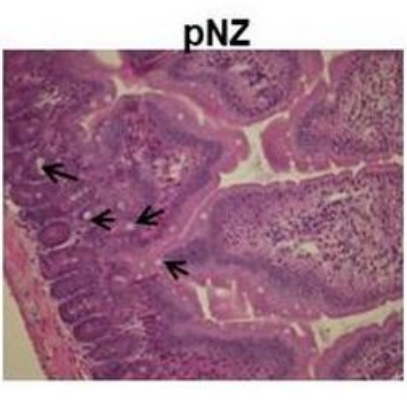

pNZ

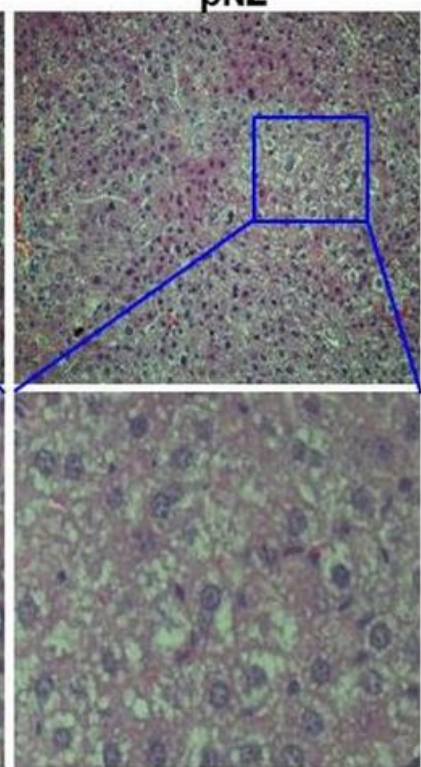

hADH1B

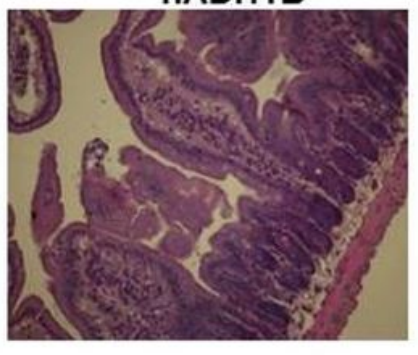

hADH1B

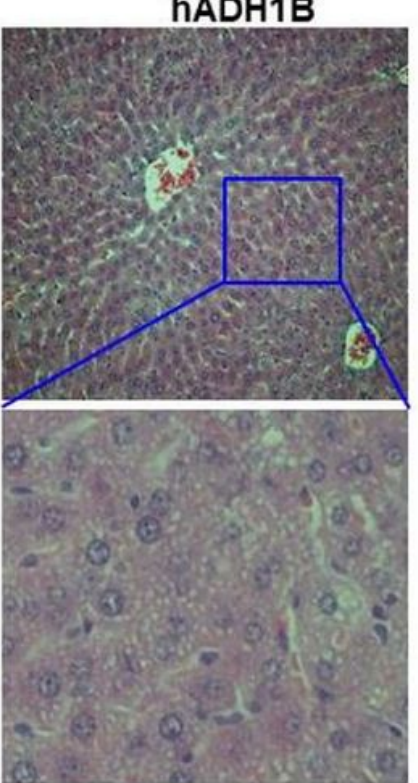

\section{Figure 4}

Oral probiotics attenuate hepatointestinal lesions associated with acute alcohol consumption. A. Time course of blood alcohol residue after drinking. B. Serum concentration of triglycerides. C. H\&E histological staining of intestinal sections. D. H\&E histological staining of liver sections. 